\title{
Pregão eletrônico e dispensa de licitação: uma análise dos valores contratados pela administração pública federal
}

\author{
Ernane Ferreira Bastos \\ Comando do Exército Brasileiro, Brasília, DF - Brasil \\ Luiz Ricardo Cavalcante \\ Consultoria Legislativa do Senado Federal, Brasília, DF - Brasil
}

O objetivo deste trabalho é analisar os valores unitários contratados em processos de aquisição por meio das modalidades de pregão eletrônico e de dispensa de licitação em unidades da administração pública federal, levando-se em consideração os volumes adquiridos em cada certame. A revisão bibliográfica indica que: i) os custos operacionais do pregão eletrônico são superiores àqueles da dispensa de licitação; e ii) a demora no processo de aquisição e o volume de compras afetam significativamente os valores unitários dos bens adquiridos. A metodologia envolve a análise de dados relativos a 14 itens que dispensam especificações complexas e tecnicamente rebuscadas. Os resultados revelam que, na ampla maioria dos casos, a quantidade afeta negativa e significativamente os valores unitários, mas a modalidade de compra não os influencia. Somente em quatro casos a modalidade de compra apresentou coeficiente estatisticamente significativo. Em um deles, inclusive, a dispensa de licitação resultou em preços menores quando se leva em consideração o volume de compras. Isso sugere que os limites de dispensa de licitação poderiam ser rediscutidos, embora seja preciso levar em consideração que o pregão eletrônico pode estar atuando como uma espécie de regulador de preços.

Palavras-chave: compras públicas, pregão eletrônico, dispensa de licitação 


\section{Electronic bidding and bidding exemption: an analysis of values of procurement processes in units of the Brazilian Federal Public Administration}

The aim of this work is to analyze the unit values of procurement processes through electronic bidding (reverse auction) and bidding exemption in units of the Brazilian Federal Public Administration, taking into account the volumes acquired in each event. The bibliographic review indicates that: i) the operating costs of the electronic bidding are higher than those of the bidding exemption; and ii) the delay in the acquisition process and the purchase volumes significantly affect the unit values of the acquired goods. The methodology involves analyzing data related to 14 items that do not require complex and technically elaborated specifications. The results reveal that, in the vast majority of cases, the quantity affects negatively and significantly the unit values, but the purchase type does not influence them. Only in four cases did the purchase type show a statistically significant coefficient. In one of them, the bidding exemption resulted in lower prices when considering the purchase volume. These results suggest that bidding exemption limits could be reviewed, although it is necessary to take into account that the reverse auction may be acting as a kind of price regulator.

Keywords: public procurement, electronic bidding, bidding exemption

\section{Exención de licitación y subasta electrónica: un análisis de los valores contratados por la Administración Pública Federal de Brasil}

El objetivo de este trabajo es analizar los valores unitarios contratados en los procesos de adquisición a través de las modalidades de subasta electrónica y exención de licitación en unidades de la Administración Pública Federal, teniendo en cuenta los volúmenes adquiridos en cada evento. La revisión bibliográfica indica que: i) los costos operativos de la subasta electrónica son más altos que los de la exención de licitación; y ii) la demora en el proceso de adquisición y el volumen de compras afectan significativamente los valores unitarios de los bienes adquiridos. Datos relacionados con 14 artículos que no requieren especificaciones complejas y técnicamente elaboradas fueran analizados. Los resultados muestran que, en la gran mayoría de los casos, la cantidad afecta de manera negativa y significativa los valores unitarios, pero el modo de compra no influye en ellos. Solo en cuatro casos la modalidad de compra mostró un coeficiente estadísticamente significativo. En uno de ellos, la renuncia a la licitación resultó en precios más bajos al considerar el volumen de compras. Esto sugiere que se podría volver a discutir los límites de la exención de licitación, aunque sea necesario tener en cuenta que la subasta electrónica puede estar actuando como una especie de regulador de precios.

Palabras clave: compras públicas, subasta electrónica, exención de licitación 


\section{Introdução}

De modo geral, a aquisição de bens e a contratação de serviços pelo governo é feita por meio de processos licitatórios em que se busca a proposta mais vantajosa para administração pública. Essa definição é convergente com aquilo que argumenta Carvalho Filho (2015, p. 20), para quem a licitação é "o procedimento administrativo vinculado por meio do qual os entes da Administração Pública e aqueles por ela controlados selecionam a melhor proposta entre as oferecidas pelos vários interessados [...]". As empresas ou os interessados em participar do processo cadastram-se e apresentam suas propostas para que a administração pública possa selecionar, no conjunto apresentado, aquela que envolva os menores custos, a qualidade adequada e a tempestividade requerida, por exemplo. Trata-se, desse modo, de identificar a proposta mais vantajosa (que não necessariamente se confunde com aquela com menores preços).

No Brasil, as compras e contratações públicas, em regra, devem ser realizadas por meio de licitações. A Lei no 8.666/1993, conhecida como Lei de Licitações, é a base para todas as formas de contratação. No artigo 22 desta lei estão previstas cinco modalidades de licitação: concorrência, tomada de preços, convite, concurso e leilão. Todas essas modalidades possuem rito específico e o gestor público deve observar, na escolha da modalidade, entre outras características, o valor estimado durante a fase interna da licitação.

Nove anos mais tarde, a Lei n $10.520 / 2002$ criou a modalidade de licitação pregão. Nessa modalidade, diferentemente das demais, havia uma inversão das fases: primeiro era ordenada a melhor proposta financeira e só então se solicitava a documentação de habilitação apenas da licitante mais bem colocada. Esse modelo reduziu os custos dos procedimentos associados ao próprio processo licitatório e o tornou mais ágil. Por meio do Decreto no 5.450/2005, instituiu-se o pregão eletrônico. Essa modalidade possibilitou maior transparência, celeridade e aumento do número de concorrentes. Trata-se de uma das faces do fenômeno descrito por Baily et al. (2008, p. 371), que afirmam que "[...] o advento da tecnologia de informação (TI) e de sistemas de softwares mais integrados tem mudado radicalmente a área de compras". 
Outro instrumento é a dispensa de licitação, prevista nos incisos I ell do artigo 24 da Lei no 8.666/1993. Esses dispositivos fixam também, com base nos limites de enquadramento das modalidades de licitação, os casos em que se pode recorrer à dispensa de licitação. Essa possibilidade pode ser avocada com base em 35 incisos que envolvem, por exemplo, casos de emergência, calamidade pública ou comprometimento da segurança nacional. Neste trabalho, em particular, o foco recai sobre os casos enquadrados no inciso II do artigo 24 da Lei nㅇ 8.666/1993:

Art. 24. É dispensável a licitação: I - Para obras e serviços de engenharia de valor até $10 \%$ (dez por cento) do limite previsto na alínea "a", do inciso I do artigo anterior, desde que não se refiram a parcelas de uma mesma obra ou serviço ou ainda para obras e serviços da mesma natureza e no mesmo local que possam ser realizadas conjunta e concomitantemente; II - Para outros serviços e compras de valor até $10 \%$ (dez por cento) do limite previsto na alínea "a", do inciso II do artigo anterior e para alienações, nos casos previstos nesta Lei, desde que não se refiram a parcelas de um mesmo serviço, compra ou alienação de maior vulto que possa ser realizada de uma só vez; [...].

Com base nos valores definidos no Decreto no 9.412/2018 como limites para as várias modalidades de licitação previstas na Lei no 8.666/1993, a dispensa de licitação pode ser adotada para obras e serviços de engenharia e para outros serviços e compras. No primeiro caso, o limite em vigor é de $\mathrm{R} \$ 33$ mil, ao passo que, no segundo, é de $\mathrm{R} \$ 17,6$ mil.

Em princípio, a vantagem da dispensa de licitação é a redução dos custos operacionais associados ao processo de aquisição de bens ou de contratação de serviços. Trata-se aqui das exigências legais de pesquisas de mercado, de pareceres jurídicos e de publicações de editais em periódicos, por exemplo. Porém, ainda que se recorra à chamada cotação eletrônica - que tende a inibir a apresentação de preços fora dos padrões de mercado -, é razoável admitir que a dispensa de licitação, por envolver menores níveis de concorrência do que o pregão eletrônico, tenderia a resultar em preços maiores. É a ponderação desses custos e desses benefícios que leva Fiuza (2014, p. 10) a argumentar que o desafio da administração pública é promover a eficiência, ou seja, fazer a melhor contratação com os menores custos operacionais.

Uma ponderação dos custos operacionais e dos benefícios (resultantes dos menores preços) do uso do pregão eletrônico em relação à dispensa de licitação (cujos custos 
operacionais seriam menores, mas que tenderia a implicar em preços maiores) foi feita pela CGU (CONTROLAdorIA GERAL DA UnIÃo, 2017). Esse estudo amparou a revisão, em 2018, dos limites dos valores que poderiam ser objeto de dispensa de licitação.

O pressuposto desse tipo de análise é que o valor unitário contratado no pregão eletrônico é sempre menor do que o valor unitário contratado por meio da dispensa de licitação. Trata-se daquilo que a CGU (2017) chama de "desconto médio". Embora essa seja uma premissa razoável, o fato é que a comparação desses preços tem sido objeto de uma produção bibliográfica reduzida. Além disso, mesmo confirmada a premissa de que o pregão eletrônico efetivamente traz um desconto, a estimativa de sua magnitude é fundamental para que se possa confrontá-lo com a eventual redução de custos operacionais obtida com a dispensa de licitação. Esse tipo de análise é mais abrangente do que uma simples comparação de preços médios em um caso e no outro, porque, conforme se evidencia na seção 2 deste trabalho, os preços unitários são afetados por outros fatores (e não apenas pela modalidade de compra).

Diante dessas questões, o objetivo deste trabalho é analisar os valores unitários contratados em processos de aquisição por meio das modalidades de pregão eletrônico e de dispensa de licitação em unidades da administração pública federal. Pretende-se, desse modo, verificar se há diferenças estatisticamente significativas de preços entre essas duas modalidades levando-se em consideração os volumes adquiridos em cada certame. $\mathrm{O}$ trabalho está estruturado em mais quatro seções além desta introdução. $\mathrm{Na}$ seção 2, reúnem-se os fundamentos que amparam a análise. Busca-se, em particular, identificar trabalhos que tenham comparado preços unitários nas diferentes modalidades de licitação, que tenham identificado fatores que os afetam e que analisem os custos operacionais do pregão eletrônico e da dispensa de licitação. Na seção 3, descrevem-se os procedimentos metodológicos adotados, que envolvem i) a coleta de dados relativos a 14 itens que dispensam especificações complexas e tecnicamente rebuscadas; e ii) a análise desses dados com base em técnicas econométricas que permitem isolar o efeito da modalidade de licitação nos preços unitários. Na seção 4, apresentam-se os resultados e, finalmente, na quinta seção destacam-se as principais conclusões do trabalho. 


\section{Fundamentos}

Conforme se indicou na introdução deste trabalho, há evidências de que os custos operacionais do pregão eletrônico são superiores àqueles da dispensa de licitação. Os trabalhos que amparam essa percepção são brevemente analisados na seção 2.1. Essas análises, contudo, comparam a eficiência das duas modalidades com base nos preços médios, e não levam em consideração os outros fatores que poderiam afetar os preços unitários. Para tratar desse tema, a seção 2.2 resume os resultados de alguns trabalhos que indicam que aspectos como a demora no processo de aquisição e o volume de compras influenciam os valores contratados.

\subsection{Custos operacionais}

De acordo com Alegria (2016, p. 41), o custo de uma licitação, levando-se em conta os gastos com pessoal, com materiais de expediente, com concessionárias de serviço público, entre outros, seria de $\mathrm{R} \$ 15.058,04$. Esse é um valor importante, tendo-se em vista que uma licitação será eficiente se as vantagens que trouxer para a administração superarem custos operacionais. Isso quer dizer que, ao final da licitação, os ganhos com descontos oriundos da diferença entre o valor de referência (ou de mercado) e a proposta do fornecedor devem, no mínimo, ser maiores que o valor de seus custos operacionais.

Nesse escopo, a CGU (2017) mensurou a eficiência (i.e., a relação entre custos operacionais e benefícios) da realização de pregões pelo Governo Federal, comparandoos com os custos operacionais das aquisições diretas, ou seja, daquelas feitas por dispensa de licitação. Para isso, a CGU (2017) definiu a eficiência do pregão com base na seguinte fórmula:

Ef.pregão $=($ benef. pregão - benef.dispensa $)-($ custo pregão - custo dispensa $)$

O benefício do pregão corresponde ao ganho obtido entre o valor de referência (valor orçado) e a queda do preço (desconto) ao término do pregão (calculado com base nos valores médios), de acordo com a seguinte equação:

Benef. pregão $=$ valor da compra $\times$ desconto médio 
O benefício da dispensa é definido como zero, uma vez que se assume que o valor da compra é exatamente igual ao que é ofertado pelo fornecedor.

Os custos do pregão e da dispensa foram calculados de forma semelhante; em ambos os casos, os parâmetros são a duração do processo, a quantidade de servidores envolvidos, o percentual de tempo dedicado à condução do processo e o salário médio por dia pago aos servidores:

Custo pregão $=$ dur. processo $\times$ qtd. servidores $\times$ perc. tempo dedicado $\times$ salário dia Custo dispensa $=$ dur. processo $\times$ qtd. servidores $\times$ perc. tempo dedicado $\times$ salário dia

No caso do pregão, a CGU (2017) estimou a duração do processo nas fases interna e externa em 74 dias, a quantidade de servidores envolvidos em 2,0 e o percentual de tempo dedicado em $25 \%$. Já no caso da dispensa, a duração do processo foi estimada em três dias, a quantidade de servidores envolvidos em 1,0 e o percentual de tempo dedicado em $100 \%$.

A CGU (2017) projetou vários cenários e testou três valores como limites para dispensa de licitação (R\$ 8 mil, R\$ 26 mil e R\$ 52 mil). Nas três situações, constatou-se, com base no modelo proposto, que os órgãos compram de forma deficitária, ou seja, os ganhos com a diferença do valor de referência obtido no mercado e as propostas dos licitantes seriam menores que a diferença de custos operacionais entre o pregão e a dispensa. No caso do limite mais alto (R\$ 52 mil), 63\% dos órgãos contratariam de forma superavitária se optassem pela dispensa de licitação.

Esses resultados ampararam a fixação de novos limites para as várias modalidades de licitação (e, por conseguinte, para a dispensa de licitação) por meio da edição do Decreto $n$ ㅇ 9.412/2018. A dispensa de licitação para obras e serviços de engenharia, que era de $\mathrm{R} \$ 15 \mathrm{mil}$, passou para $\mathrm{R} \$ 33 \mathrm{mil}$; e para outras contratações passou de $\mathrm{R} \$ 8 \mathrm{mil}$ para $\mathrm{R} \$ 17,6$ mil. Contudo, conforme se observou, todo o trabalho ampara-se na premissa de que o pregão eletrônico gera um desconto médio em relação aos preços praticados na dispensa de licitação. Na seção subsequente, analisam-se trabalhos que exploraram as diferenças de preços entre essas duas modalidades e os fatores que as explicariam. 


\subsection{Fatores que afetam os preços unitários}

Há uma quantidade relativamente escassa de trabalhos que analisam empiricamente os fatores que afetam os preços unitários em processos de licitação. Com efeito, a maior parte da literatura sobre o tema adota uma abordagem essencialmente jurídica ou doutrinária (KUHN, 2018; ALEXANDRE, 2016) ou simplesmente assume que maiores níveis de competição entre fornecedores estão associados a menores preços (ALBANO; SPARRO, 2008). Desse modo, os trabalhos que analisam especificamente o impacto da modalidade de licitação nos preços unitários são raros e inconclusivos. Ainda assim, foram identificados trabalhos que apontam, no conjunto dos fatores que afetam esses preços, os seguintes aspectos: i) demora no processo de aquisição; e ii) volume de compras (economias de escala e de escopo). Esses aspectos podem ser sintetizados na expressão "estrutura de governança", que é aquela empregada por Bandiera, Prat e Valleti (2009) ao apontarem os fatores que levam órgãos públicos a pagarem mais por certos produtos do que outros.

Ao analisarem as taxas de sucesso e de fracasso nas licitações de medicamentos realizadas em 2012 por um hospital universitário do Estado de São Paulo, Arantes et al. (2019, p. 2) indicam que "vários fatores podem interferir no processo de gestão e aumento dos gastos com a aquisição de medicamentos". Assim, embora não investiguem diretamente os fatores que afetam os preços unitários em processos de licitação, esses autores fornecem elementos sobre esse assunto. No conjunto desses fatores, apontamse i) falta de organização e estruturação dos serviços farmacêuticos (que pode ser considerado específico das compras por hospitais); ii) falta de planejamento; iii) demora no processo de aquisição; iv) compras frequentes em pequenas quantidades, em regime de urgência; v) falta constante de medicamentos; e vi) falta de um sistema eficiente de controle e informação.

A demora no processo de aquisição é frequente nos processos licitatórios em decorrência das exigências do cumprimento de suas várias fases e do aumento constante da judicialização. Mesmo no caso do pregão eletrônico (cujo rito é relativamente simplificado), a CGU (2017) assume uma duração média do processo de 74 dias. O intervalo entre o momento da apresentação da proposta e de sua consumação leva os fornecedores a aumentarem seus valores, pois acabam levando em conta incertezas jurídicas (alterações de normativos, por exemplo) e econômicas (flutuações de taxas de juros e de câmbio ou alterações nas alíquotas de tributos, por exemplo). 
Na prática, no pregão eletrônico conduzido no Brasil com o sistema de registro de preços, os lances permanecem válidos por um período de até 12 meses sem que a administração precise, necessariamente, adquirir os produtos. Essas incertezas acabam sendo incorporadas aos preços e muitas vezes impedem a consumação da compra. Barbosa (2016) segue o mesmo raciocínio quando ratifica que a pesquisa de preços pode causar uma falsa comparação com o mercado. A autora afirma que diversos fornecedores, ao serem requisitados a encaminhar pesquisas de preços para planejamento de processo licitatório, sabendo tratar-se de dados para compor procedimento administrativo do certame, ou seja, que não se trata de compra imediata, informam valores acima do mercado. Há também a possibilidade de que os fornecedores, ao serem solicitados a enviar propostas de preços, não as encaminhem ou nem mesmo informem que não vão encaminhá-las, gerando retardo na condução dos processos. Isso reduz a competição e tende a contribuir para a elevação dos preços.

Embora não explorem em detalhes esse aspecto, Arantes et al. (2019) apontam também compras frequentes em pequenas quantidades como um fator que pode influenciar os preços. Da mesma forma, Faria et al. (2010) argumentam que a quantidade aumenta o poder de barganha da administração junto aos licitantes. Esse é também o argumento usado por Cibils (2019, p. 45), que afirma que processos com maior quantidade de itens são mais competitivos, "pois os fornecedores vislumbram a oportunidade de serem vencedores de vários itens e firmar um contrato com a administração". Trata-se, nesse caso, de um aspecto diretamente relacionado ao planejamento (que deve, em tese, levar em conta aspectos como projeções de demanda, custos de estocagem e perecibilidade, por exemplo) e que se relaciona diretamente com o volume adquirido. Assume-se, nesse caso, que compras maiores tendem a resultar em preços unitários menores. Economias de escala (i.e., associadas a maiores quantidades de um mesmo item) ou de escopo (associadas a maiores quantidades de itens ofertados pelo mesmo fornecedor) tendem, de fato, a implicar menores preços unitários porque permitem que custos fixos associados aos processos de venda sejam diluídos.

Por fim, Paz (2016), ao analisar a experiência adquirida com a utilização do pregão eletrônico nas aquisições de bens das unidades gestoras do Exército brasileiro sediadas no Estado do Rio de Janeiro, argumenta que as aquisições realizadas utilizando o pregão eletrônico foram mais vantajosas (em termos de preços médios de quatro produtos 
padronizados) do que as aquisições por dispensa de licitação. Contudo, o autor argumenta que nem todas as unidades gestoras alcançam o mesmo nível de eficiência e atribui as diferenças, entre outros fatores, a deficiências nas pesquisas de preços.

Em resumo, na prática, os fatores mais frequentemente mencionados são a demora no processo de aquisição e o volume de compras. Desse modo, embora o pregão eletrônico seja, em tese, favorecido por maiores volumes de compras (que tendem a gerar preços unitários menores), a dispensa de licitação, por ser mais rápida e por não envolver as incertezas associadas ao pregão eletrônico, pode também, em determinados casos, resultar em preços unitários menores.

\section{Procedimentos metodológicos}

A metodologia de pesquisa adotada para analisar os valores unitários contratados em processos de aquisição por meio das modalidades de pregão eletrônico e de dispensa de licitação em unidades da administração pública federal envolveu:

- a coleta de dados relativos a 14 itens que dispensam especificações complexas e tecnicamente rebuscadas; e

- a análise desses dados utilizando técnicas econométricas capazes de isolar o impacto das diferentes modalidades de licitação nos valores contratados.

Esses procedimentos são descritos nas seções 3.1 e 3.2, a seguir.

\subsection{Coleta de dados}

A coleta de dados seguiu as diretrizes abaixo:

- Os dados foram extraídos da plataforma "Painel de Preços" do Ministério da Economia, que torna públicos os preços de todos os bens adquiridos e de todos os serviços contratados pela administração pública federal. 
- Selecionaram-se 14 bens que dispensam especificações complexas e tecnicamente rebuscadas (açúcar, água sanitária, água mineral, álcool, café, caneta, copo, detergente, esponja, feijão, marca-texto, papel A4, pilha e quadro branco).

- O período de análise foi circunscrito ao ano de 2019.

Para a extração dos dados, usaram-se os códigos do Catálogo de Materiais (CATMAT) do Sistema Integrado de Administração de Serviços Gerais (Siasg) do Ministério da Economia (BRASIL, 2012). Embora identifiquem e padronizem as características dos materiais, esses códigos, por vezes, não são suficientemente claros, sendo necessárias informações adicionais no momento de divulgar a compra. Por outro lado, em alguns casos, existem códigos diferentes, porém os materiais são praticamente os mesmos. A diferença pode estar associada a algum detalhe ou característica complementar (por exemplo, "furo no corpo cilíndrico da caneta esferográfica"). O Quadro 1 mostra um exemplo de vários códigos que dizem respeito essencialmente ao mesmo produto e que não afetam significativamente seu preço.

\section{Quadro 1 | Exemplo de identificação dos códigos CATMAT para "caneta esferográfica"}

\section{Código CATMAT Descrição dos códigos}

Caneta esferográfica, material: plástico, quantidade cargas: 1 un, material

288155 ponta: aço inoxidável com esfera de tungstênio, tipo escrita: média, cor tinta: azul, características adicionais: corpo cilíndrico, transparente e orifício lateral

Caneta esferográfica, material: plástico, quantidade cargas: 1 un, material

288156 ponta: aço inoxidável com esfera de tungstênio, tipo escrita: média, cor tinta: preta, características adicionais: corpo cilíndrico, transparente e orifício lateral

Caneta esferográfica, material: plástico, quantidade cargas: 1 un, material 288157 ponta: aço inoxidável com esfera de tungstênio, tipo escrita: média, cor tinta: vermelha, características adicionais: corpo cilíndrico, transparente e orifício lateral 


\begin{tabular}{ll}
\hline Código CATMAT & Descrição dos códigos \\
289210 & Caneta esferográfica, material: plástico, quantidade cargas: 1 un, material \\
& ponta: esfera de tungstênio, tipo escrita: média, cor tinta: preta \\
\hline 289211 & Caneta esferográfica, material: plástico, quantidade cargas: 1 un, material \\
& ponta: esfera de tungstênio, tipo escrita: média, cor tinta: vermelha \\
& Caneta esferográfica, material: plástico, quantidade cargas: 1 un, material \\
& ponta: aço inoxidável com esfera de tungstênio, tipo escrita: média, cor \\
& tinta: azul, características adicionais: corpo sextavado, transparente e \\
& orifício lateral \\
289405 & Caneta esferográfica, material: plástico, quantidade cargas: 1 un, material \\
& ponta: aço inoxidável com esfera de tungstênio, tipo escrita: média, cor \\
& tinta: preta, características adicionais: corpo sextavado, transparente e \\
& orifício lateral \\
& Caneta esferográfica, material: plástico, quantidade cargas: 1 un, material \\
& ponta: aço inoxidável com esfera de tungstênio, tipo escrita: média, cor \\
& tinta: vermelha, características adicionais: corpo sextavado, transparente e \\
& orifício lateral
\end{tabular}

Fonte: elaborado pelos autores.

Diante dessa constatação, adotou-se, neste trabalho, o seguinte procedimento:

- Quando foi possível encontrar código CATMAT que gerou mais de 30 aparições de aquisições de materiais, tanto para pregão como para a dispensa de licitação, utilizou-se somente um código.

- Porém, quando não se encontrou um código capaz de gerar, no mínimo, 30 aparições em cada uma das modalidades de licitação, foi necessário identificar pelo menos mais um código que, em sua descrição, não contivesse especificações que modificassem as características básicas do material e que não influenciassem o preço ofertado.

- Quando não foi possível encontrar outro código que permitisse comparar os preços em condições de igualdade, descartou-se o material da pesquisa.

Essa sistemática permitiu que somente se comparassem itens essencialmente idênticos em cada um dos 14 casos. 
O sistema gera relatórios que podem ser extraídos, por exemplo, em formato de planilha eletrônica. Esses relatórios disponibilizam as seguintes informações:

- número da compra;

- número do item dentro do processo de compra;

- modalidade (pregão ou dispensa de licitação);

- código do material;

- descrição do item;

- quantidade;

- valor contratado;

- $\quad$ nome do fornecedor;

- órgão;

- unidade gestora;

- data da compra, entre outros.

Uma vez definidos os códigos a serem usados, aplicaram-se, no Painel de Preços, os seguintes filtros:

- material propriamente dito e seu(s) código(s) CATMAT;

- $\quad$ unidade de fornecimento;

- $\quad$ ano da contratação; e

- $\quad$ modalidade de contratação.

O ano da contratação foi restrito a 2019 e a modalidade de contratação ao "pregão" e à "dispensa de licitação". Buscaram-se materiais adquiridos por todas as unidades gestoras da administração pública federal. 
Quando a quantidade de processos ultrapassa o limite de mil, o sistema não permite a continuidade da pesquisa para a emissão dos relatórios. Embora fosse possível trabalhar com amostras sem enviesar os resultados, optou-se por trabalhar somente itens de compras em que a quantidade não ultrapassasse mil. Naturalmente, alguns itens de compra são mais frequentes do que outros. Por isso, o número de observações, em cada caso, varia de pouco mais de 150 até quase 600 (considerando a extração dos outliers descrita na próxima seção).

\subsection{Análise dos dados}

Uma primeira abordagem para analisar os valores contratados de bens idênticos em processos de aquisição seria simplesmente verificar se os valores médios seriam iguais ou diferentes dentro de determinada margem de confiança. Contudo, um procedimento dessa natureza poderia levar a conclusões enganosas, porque há outros fatores que afetam o preço unitário e podem não estar uniformemente distribuídos entre as duas modalidades. Por exemplo, conforme se evidenciou na Seção 2, os preços unitários são sensíveis ao volume de compras.

Por essa razão, neste trabalho optou-se por utilizar uma especificação em que se considera o preço unitário de cada produto $i\left(p_{i}\right)$ como variável dependente e as seguintes variáveis independentes:

- $\quad$ modalidade de aquisição $\left(m_{\mathrm{i}}\right)$ : pregão ou dispensa de licitação;

- $\quad$ quantidade total ofertada $\left(q_{\mathrm{i}}\right)$;

- trimestre da compra $\left(t_{i}\right)$, para aferir se variações de preços afetariam os resultados obtidos.

Portanto, a especificação pode ser resumida da seguinte forma:

$$
\ln \left(p_{i}\right)=\beta_{0}+\beta_{1} \ln \left(q_{i}\right)+\beta_{2} m_{i}+\beta_{3} t_{i}+\varepsilon
$$

Convém notar que não se pretendeu, neste trabalho, propor um modelo preditivo do comportamento dos preços unitários (que, possivelmente, requeria a inclusão de variáveis explicativas adicionais), mas apenas verificar se a modalidade de aquisição 
influencia significativamente o preço unitário, considerando a quantidade ofertada e o momento da compra.

Visando a identificar o modelo probabilístico mais bem ajustado aos dados relativos aos 14 produtos, foram testadas as seguintes alternativas:

- $\quad$ modelo normal linear;

- modelo gama; e

- modelo normal inverso.

O modelo normal linear é apropriado quando a variável dependente é do tipo quantitativa contínua e simétrica e, para a obtenção de bons ajustes, requer a existência de uma relação linear entre a variável dependente e as variáveis explicativas, além de o erro ter distribuição normal (CHARNET et al., 1999). Após a organização dos bancos de dados, esse modelo foi usado para o produto "açúcar" a fim de verificar a qualidade do ajuste. Verificou-se, com base na porcentagem dos pontos de resíduo fora das bandas de confiança, que o modelo normal linear não fornecia um bom ajuste tanto no caso do banco de dados completo como no caso do banco de dados do qual foram retirados os outliers. Isso ocorreu porque a variável dependente tem comportamento assimétrico. Por essa razão, optou-se por utilizar os modelos lineares generalizados (MLG).

Esses modelos são uma extensão do modelo normal linear que possibilita a utilização de outras distribuições para os erros e uma função de ligação que relaciona a média da variável dependente (resposta) à combinação linear das variáveis independentes (explicativas). Os modelos gama e normal inverso são alguns dos MLG adequados para dados do tipo quantitativo contínuo com valores positivos e assimétricos. Assim, como se identificou que a variável resposta é assimétrica e positiva, foram analisados os MLG com essas distribuições.

Foi necessário ainda mudar o tipo de transformação nos dados, pois a variável resposta (valor do produto) tem valores entre 0 e 1 na maior parte dos bancos de dados, tornando impossível a utilização dos modelos gama e normal inverso, pois os valores nesse intervalo seriam negativos ao aplicar a transformação log $(x)$. Assim, para corrigir esse problema, a transformação foi alterada para log $(x)+5$, corrigindo-se, dessa forma, 
a alta variabilidade e a escala. A função de ligação utilizada foi a logarítmica, uma vez que impede o surgimento de resultados negativos e fornece boas interpretações a partir do exponencial dos coeficientes.

Moore (2016) destaca que uma das melhores formas de se avaliar os modelos estatísticos é através do critério de informação de Akaike (AIC), que consiste em encontrar o modelo mais parcimonioso possível. Desse modo, quanto menor o valor de AIC, melhor o ajuste do modelo. ${ }^{1}$ Assim, para verificar se a distribuição utilizada em cada um dos seis tipos de modelo (com e sem outliers) estava bem ajustada, verificou-se a porcentagem de pontos de resíduos fora das bandas de confiança, em que o nível de tolerância indicado é de $5 \%$.

A Tabela 1 apresenta o $r^{2}$, o valor do AIC e a porcentagem de pontos fora do gráfico de envelope para os modelos linear, gama e normal inverso tanto no caso do banco de dados completo como no caso do banco de dados do qual foram retirados os outliers. Essa tabela foi utilizada para a escolha do modelo de análise.

Tabela 1 | Seleção de modelos

\begin{tabular}{|c|c|c|c|c|c|c|c|}
\hline & & \multicolumn{3}{|c|}{ Dados completos } & \multicolumn{3}{|c|}{ Dados sem outliers } \\
\hline & & $r^{2}$ & AIC & $\begin{array}{l}\text { Pontos } \\
\text { fora }\end{array}$ & $r^{2}$ & AIC & $\begin{array}{l}\text { Pontos } \\
\text { fora }\end{array}$ \\
\hline Variáveis & Modelos & & & & & & \\
\hline \multirow{3}{*}{ Açúcar } & Linear & 0,103 & 220,72 & $92,83 \%$ & 0,169 & 143,98 & $50,17 \%$ \\
\hline & Gama & 0,119 & 169,65 & $97,07 \%$ & 0,171 & 140,08 & $19,87 \%$ \\
\hline & $\begin{array}{l}\text { Normal } \\
\text { inverso }\end{array}$ & 0,125 & 148,12 & $89,90 \%$ & 0,172 & 142,78 & $16,50 \%$ \\
\hline \multirow{3}{*}{ Água } & Linear & 0,213 & 880,22 & $68,62 \%$ & 0,178 & 774,99 & $80,89 \%$ \\
\hline & Gama & 0,235 & 813,20 & $38,27 \%$ & 0,193 & 772,03 & $19,87 \%$ \\
\hline & $\begin{array}{l}\text { Normal } \\
\text { inverso }\end{array}$ & 0,245 & 785,08 & $23,47 \%$ & 0,200 & 700,05 & $25,92 \%$ \\
\hline
\end{tabular}

\footnotetext{
${ }^{1}$ Mais informações sobre os modelos estatísticos utilizados podem ser encontradas em Charnet et al. (1999), Cordeiro e Demétrio (2008), Hair et al. (2009) e Moore (2016).
} 


\begin{tabular}{|c|c|c|c|c|c|c|c|}
\hline & & \multicolumn{3}{|c|}{ Dados completos } & \multicolumn{3}{|c|}{ Dados sem outliers } \\
\hline & & $r^{2}$ & AIC & $\begin{array}{c}\text { Pontos } \\
\text { fora }\end{array}$ & $r^{2}$ & AIC & $\begin{array}{l}\text { Pontos } \\
\text { fora }\end{array}$ \\
\hline \multirow{3}{*}{$\begin{array}{l}\text { Água } \\
\text { sanitária }\end{array}$} & Linear & 0,204 & 281,61 & $92,71 \%$ & 0,317 & 48,39 & $26,37 \%$ \\
\hline & Gama & 0,243 & 233,18 & $89,06 \%$ & 0,325 & 40,52 & $13,74 \%$ \\
\hline & $\begin{array}{l}\text { Normal } \\
\text { inverso }\end{array}$ & 0,258 & 214,28 & $79,17 \%$ & 0,328 & 37,07 & $2,75 \%$ \\
\hline \multirow{3}{*}{ Álcool } & Linear & 0,238 & 383,37 & $93,48 \%$ & 0,332 & 100,58 & $22,28 \%$ \\
\hline & Gama & 0,258 & 337,49 & $91,06 \%$ & 0,339 & 85,97 & $0,99 \%$ \\
\hline & $\begin{array}{l}\text { Normal } \\
\text { inverso }\end{array}$ & 0,266 & 317,70 & $84,78 \%$ & 0,340 & 80,04 & $0,50 \%$ \\
\hline \multirow{3}{*}{ Café } & Linear & 0,195 & 46,80 & $71,34 \%$ & 0,177 & $-53,84$ & $5,42 \%$ \\
\hline & Gama & 0,201 & 40,40 & $49,68 \%$ & 0,177 & $-54,11$ & $2,03 \%$ \\
\hline & $\begin{array}{l}\text { Normal } \\
\text { inverso }\end{array}$ & 0,203 & 37,59 & $57,32 \%$ & 0,177 & $-54,16$ & $2,70 \%$ \\
\hline \multirow{3}{*}{ Caneta } & Linear & 0,257 & 1867,11 & $21,40 \%$ & 0,242 & 1728,16 & $13,76 \%$ \\
\hline & Gama & 0,281 & 1740,50 & $31,51 \%$ & 0,260 & 1634,50 & $41,99 \%$ \\
\hline & $\begin{array}{l}\text { Normal } \\
\text { inverso }\end{array}$ & 0,279 & 1706,10 & $59,08 \%$ & 0,260 & 1608,10 & $55,05 \%$ \\
\hline \multirow{3}{*}{ Copo } & Linear & 0,174 & 200,91 & $95,19 \%$ & 0,292 & $-72,66$ & $14,53 \%$ \\
\hline & Gama & 0,209 & 154,49 & $90,37 \%$ & 0,293 & $-75,40$ & $1,12 \%$ \\
\hline & $\begin{array}{l}\text { Normal } \\
\text { inverso }\end{array}$ & 0,223 & 135,38 & $67,38 \%$ & 0,294 & $-76,55$ & $0,00 \%$ \\
\hline \multirow{3}{*}{ Detergente } & Linear & 0,252 & 97,17 & $69,37 \%$ & 0,255 & $-77,85$ & $25,35 \%$ \\
\hline & Gama & 0,277 & 64,31 & $57,21 \%$ & 0,259 & $-82,96$ & $10,80 \%$ \\
\hline & $\begin{array}{l}\text { Normal } \\
\text { inverso }\end{array}$ & 0,287 & 50,95 & $32,43 \%$ & 0,261 & $-85,23$ & $13,15 \%$ \\
\hline \multirow{3}{*}{ Esponja } & Linear & 0,234 & 309,13 & $75,00 \%$ & 0,176 & 120,94 & $31,65 \%$ \\
\hline & Gama & 0,289 & 255,34 & $64,29 \%$ & 0,188 & 109,27 & $5,70 \%$ \\
\hline & $\begin{array}{l}\text { Normal } \\
\text { inverso }\end{array}$ & 0,308 & 234,75 & $12,50 \%$ & 0,194 & 103,85 & $2,53 \%$ \\
\hline
\end{tabular}




\begin{tabular}{|c|c|c|c|c|c|c|c|}
\hline & & \multicolumn{3}{|c|}{ Dados completos } & \multicolumn{3}{|c|}{ Dados sem outliers } \\
\hline & & $r^{2}$ & AIC & $\begin{array}{c}\text { Pontos } \\
\text { fora }\end{array}$ & $r^{2}$ & AIC & $\begin{array}{c}\text { Pontos } \\
\text { fora }\end{array}$ \\
\hline \multirow{3}{*}{ Feijão } & Linear & 0,215 & 177,24 & $2,34 \%$ & - & - & - \\
\hline & Gama & 0,216 & 117,31 & $0,39 \%$ & - & - & - \\
\hline & $\begin{array}{l}\text { Normal } \\
\text { inverso }\end{array}$ & 0,217 & 117,32 & $0,00 \%$ & - & - & - \\
\hline \multirow{3}{*}{ Marca-texto } & Linear & 0,212 & 343,73 & $97,04 \%$ & 0,318 & 32,72 & $84,98 \%$ \\
\hline & Gama & 0,114 & 558,64 & $95,39 \%$ & 0,326 & 18,47 & $61,09 \%$ \\
\hline & $\begin{array}{l}\text { Normal } \\
\text { inverso }\end{array}$ & 0,045 & 858,09 & $99,67 \%$ & 0,330 & 12,16 & $52,90 \%$ \\
\hline \multirow{3}{*}{ Papel A4 } & Linear & 0,048 & 424,16 & $99,58 \%$ & 0,295 & $-765,55$ & $3,86 \%$ \\
\hline & Gama & 0,013 & 1061,00 & $99,58 \%$ & 0,296 & $-767,38$ & $0,45 \%$ \\
\hline & $\begin{array}{l}\text { Normal } \\
\text { inverso }\end{array}$ & 0,003 & 1735,10 & $99,79 \%$ & 0,296 & $-768,02$ & $0,23 \%$ \\
\hline \multirow{3}{*}{ Pilha } & Linear & 0,248 & 1326,78 & $63,31 \%$ & 0,210 & 1151,08 & $1,72 \%$ \\
\hline & Gama & 0,266 & 1257,70 & $2,40 \%$ & 0,211 & 1133,90 & $0,74 \%$ \\
\hline & $\begin{array}{l}\text { Normal } \\
\text { inverso }\end{array}$ & 0,265 & 1240,70 & $0,24 \%$ & 0,210 & 1132,20 & $0,98 \%$ \\
\hline \multirow{3}{*}{$\begin{array}{l}\text { Quadro } \\
\text { branco }\end{array}$} & Linear & 0,058 & 923,46 & $2,97 \%$ & 0,063 & 872,93 & $7,00 \%$ \\
\hline & Gama & 0,056 & 934,76 & $1,32 \%$ & 0,063 & 871,39 & $1,33 \%$ \\
\hline & $\begin{array}{l}\text { Normal } \\
\text { inverso }\end{array}$ & 0,054 & 944,19 & $5,94 \%$ & 0,063 & 871,80 & $3,00 \%$ \\
\hline
\end{tabular}

Fonte: elaborado pelos autores.

Conforme se pode observar, na ampla maioria dos casos o modelo normal inverso proporcionou o melhor ajuste. Somente em dois casos o modelo gama forneceu um ajuste levemente superior. Por essa razão, optou-se por usar, em todos os casos, o modelo normal inverso. 


\section{Resultados}

Os resultados da análise dos valores unitários contratados em processos de aquisição por meio das modalidades de pregão eletrônico e de dispensa de licitação em unidades da administração pública federal são reportados nesta seção. Inicialmente, descreve-se a amostra utilizada e comparam-se os valores unitários médios dos 14 produtos selecionados em cada uma das modalidades analisadas (Seção 4.1). Em seguida, discutem-se os resultados da análise amparada no modelo que leva em consideração a influência de outros fatores - especialmente dos volumes adquiridos em cada certame nos preços unitários (Seção 4.2).

\subsection{Descrição da amostra}

A amostra foi composta por 4.375 compras dos produtos selecionados em 2019. A maior parte das compras realizadas empregou a modalidade pregão eletrônico (74,99\%) e somente $25,01 \%$ do total foi feita por dispensa de licitação. A Tabela 2 registra esses dados para o conjunto dos 14 produtos selecionados e para cada um deles individualmente.

Tabela 2 | Caracterização da amostra

\begin{tabular}{lccccc}
$\begin{array}{l}\text { Item } \\
\text { comprado }\end{array}$ & N (total) & $\begin{array}{c}\mathrm{n} \text { (pregão } \\
\text { eletrônico) }\end{array}$ & $\begin{array}{c}\mathrm{n} \text { (dispensa de } \\
\text { licitação) }\end{array}$ & $\begin{array}{c}\% \text { (pregão } \\
\text { eletrônico) }\end{array}$ & $\begin{array}{c}\% \text { (dispensa } \\
\text { de licitação) }\end{array}$ \\
\hline Geral & 4.375 & 3.281 & 1.094 & $74,99 \%$ & $25,01 \%$ \\
\hline Açúcar & 307 & 209 & 98 & $68,08 \%$ & $31,92 \%$ \\
\hline Água mineral & 392 & 349 & 43 & $89,03 \%$ & $10,97 \%$ \\
\hline Água sanitária & 192 & 125 & 67 & $65,10 \%$ & $34,90 \%$ \\
\hline Álcool & 414 & 316 & 98 & $76,33 \%$ & $23,67 \%$ \\
\hline Café & 157 & 116 & 41 & $73,89 \%$ & $26,11 \%$ \\
\hline Caneta & 584 & 419 & 165 & $71,75 \%$ & $28,25 \%$ \\
\hline Copo & 187 & 155 & 32 & $82,89 \%$ & $17,11 \%$ \\
\hline Detergente & 222 & 170 & 52 & $76,58 \%$ & $23,42 \%$ \\
\hline Esponja & 168 & 128 & 40 & $76,19 \%$ & $23,81 \%$
\end{tabular}




\begin{tabular}{lccccc}
$\begin{array}{l}\text { Item } \\
\text { comprado }\end{array}$ & N (total) & $\begin{array}{c}\mathrm{n} \text { (pregão } \\
\text { eletrônico) }\end{array}$ & $\begin{array}{c}\mathrm{n} \text { (dispensa de } \\
\text { licitação) }\end{array}$ & $\begin{array}{c}\% \text { (pregão } \\
\text { eletrônico) }\end{array}$ & $\begin{array}{c}\% \text { (dispensa } \\
\text { de licitação) }\end{array}$ \\
\hline Feijão & 256 & 185 & 71 & $72,27 \%$ & $27,73 \%$ \\
\hline Marca-texto & 304 & 214 & 90 & $70,39 \%$ & $29,61 \%$ \\
\hline Papel A4 & 471 & 363 & 108 & $77,07 \%$ & $22,93 \%$ \\
\hline Pilha & 417 & 304 & 113 & $72,90 \%$ & $27,10 \%$ \\
$\begin{array}{l}\text { Quadro } \\
\text { branco }\end{array}$ & 304 & 228 & 76 & $75,00 \%$ & $25,00 \%$
\end{tabular}

Fonte: elaborado pelos autores.

Conforme se pode observar, o número de compras por produto varia entre 584 (caneta) e 157 (café). A água mineral foi o produto mais frequentemente adquirido por pregão eletrônico (89,03\%), ao passo que a água sanitária foi aquele para o qual a dispensa de licitação teve o percentual mais elevado (34,90\%), embora ainda minoritário. Em todos os casos, buscou-se manter um número de compras suficientemente elevado para garantir a significância da análise. Com efeito, o menor número de compras foi observado no caso da esponja com dispensa de licitação (40).

A Tabela 3 a seguir apresenta os preços unitários médios e os desvios padrão dos 14 itens selecionados (inclusive segmentados por modalidade). Indica-se, além disso, se há diferença significativa entre as médias das duas modalidades.

Tabela 3 | Preços unitários (médias e desvios-padrão), R\$ correntes, 2019

\begin{tabular}{lcllllll}
\hline Variáveis & $\begin{array}{l}\text { Média } \\
\text { (geral) }\end{array}$ & $\begin{array}{l}\text { Desvio- } \\
\text { padrão } \\
\text { (geral) }\end{array}$ & $\begin{array}{l}\text { Média } \\
\text { (pregão) }\end{array}$ & $\begin{array}{l}\text { Desvio- } \\
\text { padrão } \\
\text { (pregão) }\end{array}$ & $\begin{array}{l}\text { Média } \\
\text { (dispensa) }\end{array}$ & $\begin{array}{l}\text { Desvio- } \\
\text { padrão } \\
\text { (dispensa) }\end{array}$ & p-valor ${ }^{1}$ \\
\hline Açúcar & 2,46 & 0,56 & 2,40 & 0,54 & 2,58 & 0,57 & $0,002 *$ \\
\hline $\begin{array}{l}\text { Água } \\
\text { mineral }\end{array}$ & 1,50 & 1,91 & 1,51 & 1,92 & 1,47 & 1,97 & 0,102 \\
\hline $\begin{array}{l}\text { Água } \\
\text { sanitária }\end{array}$ & 1,72 & 0,64 & 1,54 & 0,54 & 2,06 & 0,70 & $<0,001 *$ \\
\hline Álcool & 5,94 & 2,29 & 5,54 & 1,87 & 7,24 & 2,97 & $<0,001 *$ \\
\hline Café & 7,06 & 1,53 & 6,90 & 1,46 & 7,58 & 1,65 & $0,035 *$ \\
\hline Caneta & 3,31 & 6,44 & 2,85 & 5,99 & 4,49 & 7,39 & $<0,001 *$ \\
\hline
\end{tabular}




\begin{tabular}{|c|c|c|c|c|c|c|c|}
\hline Variáveis & $\begin{array}{l}\text { Média } \\
\text { (geral) }\end{array}$ & $\begin{array}{l}\text { Desvio- } \\
\text { padrão } \\
\text { (geral) }\end{array}$ & $\begin{array}{l}\text { Média } \\
\text { (pregão) }\end{array}$ & $\begin{array}{l}\text { Desvio- } \\
\text { padrão } \\
\text { (pregão) }\end{array}$ & $\begin{array}{l}\text { Média } \\
\text { (dispensa) }\end{array}$ & $\begin{array}{l}\text { Desvio- } \\
\text { padrão } \\
\text { (dispensa) }\end{array}$ & $p$-valor ${ }^{1}$ \\
\hline Copo & 1,36 & 0,31 & 1,30 & 0,27 & 1,64 & 0,34 & $<0,001 *$ \\
\hline Detergente & 1,30 & 0,31 & 1,25 & 0,31 & 1,44 & 0,28 & $<0,001 *$ \\
\hline Esponja & 0,50 & 0,24 & 0,47 & 0,22 & 0,59 & 0,26 & $0,001 *$ \\
\hline Feijão & 5,41 & 1,70 & 5,21 & 1,97 & 6,31 & 1,32 & $<0,001 *$ \\
\hline $\begin{array}{l}\text { Marca- } \\
\text { texto }\end{array}$ & 1,01 & 0,36 & 0,91 & 0,28 & 1,26 & 0,43 & $<0,001 *$ \\
\hline Papel A4 & 16,21 & 2,36 & 15,83 & 2,18 & 17,46 & 2,52 & $<0,001 *$ \\
\hline Pilha & 10,60 & 18,83 & 10,22 & 19,17 & 11,68 & 17,87 & $0,046 *$ \\
\hline $\begin{array}{l}\text { Quadro } \\
\text { branco }\end{array}$ & 329,65 & 386,01 & 410,60 & 386,50 & 339,28 & 382,15 & $0,038 *$ \\
\hline
\end{tabular}

Observando a tabela, verifica-se que, em geral, os preços unitários dos produtos adquiridos por meio da modalidade pregão são inferiores àqueles obtidos com a dispensa de licitação. Somente em dois casos (água mineral e quadro branco), o preço unitário com dispensa de licitação foi inferior ao obtido por meio do pregão eletrônico. A diferença é estatisticamente significativa a $95 \%$ de confiança para quase todos os casos, exceto no caso da água mineral e do café. Assim, de modo geral, esses dados confirmam a percepção de que há um desconto nas compras feitas por pregão eletrônico. Contudo, conforme se mostra na próxima seção, os preços unitários menores refletem, de modo geral, os maiores volumes de compras que se fazem nessa modalidade.

\subsection{Análise por produto}

Conforme se explicitou na Seção 3.2, o modelo de análise adotado considera o valor unitário como variável dependente e a quantidade ofertada, a modalidade de compra e o trimestre de aquisição como variáveis explicativas. A análise pressupõe a exclusão de outliers e baseia-se no modelo normal inverso. 
A Tabela 4 a seguir registra os coeficientes beta $(\beta)$ e os $p$-valores da quantidade e da modalidade. ${ }^{2}$ Como o trimestre de aquisição não se revelou significativo na ampla maioria dos casos, optou-se por não incluir essa variável na tabela e apenas comentar alguns casos específicos. A variável "pregão" foi colocada como referência. Nesse caso, a interpretação é: se o $\beta$ da modalidade for negativo, significa que a variável influencia o preço para uma tendência de valor menor. Se for positivo, ocorre exatamente o contrário, ou seja, o preço é influenciado para uma tendência de valor maior. ${ }^{3}$

\section{Tabela 4 | Quadro consolidado}

\begin{tabular}{lllll}
\hline & $\begin{array}{l}\text { Coeficiente } \\
\text { quantidade }\end{array}$ & $\begin{array}{l}\text { P-valor } \\
\text { (quantidade) }\end{array}$ & $\begin{array}{l}\text { Coeficiente } \\
\text { modalidade }\end{array}$ & $\begin{array}{l}\text { P-valor } \\
\text { (modalidade) }\end{array}$ \\
\hline Açúcar & $-0,005$ & $<0,001^{*}$ & 0,001 & 0,919 \\
\hline Água mineral & $-0,002$ & $<0,001^{*}$ & 0,014 & 0,537 \\
\hline Água sanitária & $-0,013$ & $<0,001^{*}$ & $-0,011$ & 0,285 \\
\hline Álcool & $-0,011$ & $<0,001^{*}$ & $-0,007$ & 0,228 \\
\hline Café & $-0,007$ & $<0,001^{*}$ & 0,003 & 0,594 \\
\hline Caneta & $-0,053$ & $<0,001 *$ & 0,015 & 0,505 \\
\hline Copo & $-0,008$ & $<0,001^{*}$ & $-0,026$ & $0,002 *$ \\
\hline Detergente & $-0,010$ & $<0,001^{*}$ & 0,000 & 0,999 \\
\hline Esponja & $-0,017$ & $<0,001 *$ & $-0,012$ & 0,499 \\
\hline Feijão & $-0,008$ & $<0,001 *$ & $-0,018$ & $0,015 *$ \\
\hline Marca-texto & $-0,013$ & $<0,001^{*}$ & $-0,033$ & $<0,001 *$ \\
\hline Papel A4 & $-0,004$ & $<0,001^{*}$ & 0,002 & 0,312 \\
\hline
\end{tabular}

\footnotetext{
${ }^{2}$ Os coeficientes beta $(\beta)$, que quantificam a força e o sentido das relações entre as variáveis explicativas e a variável resposta. Em se tratando de um MLG no qual foi utilizada a função de $\log (x)$ como função de ligação, não é possível interpretar o valor de beta diretamente. Portanto, foi necessário aplicar antes a função inversa de $\log (x)$ nos betas para se ter a informação de como cada variável independente influencia a variável dependente; por isso, foi calculado a exponencial (exp) dos betas. Os $p$-valores são a estatística utilizada para sintetizar o resultado de um teste de hipóteses. Formalmente, o $p$-valor é definido como a probabilidade de se obter a estatística de teste igual ou mais extrema que aquela observada em uma amostra, assumindo-se como verdadeira a hipótese nula. Como geralmente se define o nível de significância em 5\%, um $p$-valor menor que 0,05 gera evidências para rejeição da hipótese nula do teste; neste caso, a hipótese nula é que o valor de beta é zero (0), ou seja, a variável dependente não exerce influência na variável resposta.

${ }^{3}$ Da mesma forma, se $\circ \beta$ do trimestre for negativo, significa dizer que esse trimestre teve valores menores quando comparados ao 1 o trimestre. Se determinado $\beta$ do trimestre for positivo, significa que esse trimestre obteve valores maiores quando comparados ao 1 을 trimestre.
} 


\begin{tabular}{lllll}
\hline & $\begin{array}{l}\text { Coeficiente } \\
\text { quantidade }\end{array}$ & $\begin{array}{l}\text { P-valor } \\
\text { (quantidade) }\end{array}$ & $\begin{array}{l}\text { Coeficiente } \\
\text { modalidade }\end{array}$ & $\begin{array}{l}\text { P-valor } \\
\text { (modalidade) }\end{array}$ \\
\hline Pilha & $-0,044$ & $<0,001 *$ & 0,046 & $0,022 *$ \\
\hline Quadro branco & $-0,003$ & 0,505 & 0,032 & 0,055
\end{tabular}

Fonte: elaboração própria.

Conforme se pode observar, na ampla maioria dos casos, a quantidade afetou negativa e significativamente os valores unitários. Somente o preço do item "quadro branco" não foi influenciado pela quantidade (o p-valor, nesse caso, é de 0,505 ). Nos outros 13 itens, pode-se afirmar, a 95\% de confiança, que quanto maior a quantidade disponibilizada no certame, menor foi o preço contratado.

Por outro lado, de modo geral, a modalidade de compra não influenciou significativamente os valores unitários. Somente em quatro casos (copo, feijão, marca texto e pilha) a modalidade de compra apresentou coeficiente estatisticamente significativo. Em três desses quatro casos, os valores unitários obtidos com a dispensa de licitação foram maiores do que aqueles obtidos com o pregão eletrônico. Somente no caso da pilha, o pregão eletrônico resultou em preços significativamente maiores quando se leva em consideração o volume de compras. Ainda assim, na grande maioria dos casos, os resultados obtidos contradizem aqueles a que se pode chegar simplesmente comparando as médias de preços nas duas modalidades sem que se leve em consideração o volume de compras.

Quanto aos trimestres, parece que as variações não passaram de coincidências. De modo geral, ao longo do ano de 2019, variações de preços unitários não exibiram correlação com o momento da compra, denotando que a inflação não teve papel significativo.

\section{Conclusões}

Neste trabalho, analisaram-se os valores unitários contratados em processos de aquisição por meio da modalidade pregão eletrônico e da dispensa de licitação em unidades da administração pública federal. Pretendeu-se, desse modo, verificar se há diferenças estatisticamente significativas de preços entre essas duas modalidades levando- 
se em consideração os volumes adquiridos em cada certame.

A análise foi precedida por uma breve revisão bibliográfica, que mostrou que os custos operacionais do pregão eletrônico são superiores àqueles da dispensa de licitação. A CGU (2017), em particular, assume parâmetros que pressupõem maiores custos operacionais do pregão eletrônico porque o número de horas de trabalho dedicadas pelos servidores envolvidos é maior. Isso decorre da combinação dos fatores duração do processo, quantidade de servidores envolvidos e percentual de tempo de sua carga horária dedicado a essas atividades. Os maiores custos operacionais seriam, no modelo usado pela CGU (2017), eventualmente compensados pelos descontos observados no caso do pregão eletrônico em relação à dispensa de licitação. A revisão bibliográfica indicou ainda que a demora no processo de aquisição e o volume de compras afetam significativamente os valores unitários dos bens adquiridos. Desse modo, embora o pregão eletrônico seja, em tese, favorecido por maiores volumes de compras, a dispensa de licitação, por ser mais rápida e por não envolver as incertezas associadas àquela modalidade, pode também, em determinados casos, resultar em preços unitários menores.

Do ponto de vista metodológico, o trabalho amparou-se i) na coleta de dados relativos a 14 itens que dispensam especificações complexas e tecnicamente rebuscadas; e ii) na análise desses dados utilizando técnicas econométricas capazes de isolar o impacto das diferentes modalidades de licitação nos valores contratados.

Os resultados obtidos revelam que, na ampla maioria dos casos, a quantidade afetou negativa e significativamente os valores unitários. Somente em um caso o preço não foi influenciado pela quantidade. Por outro lado, de modo geral, a modalidade de compra não influenciou significativamente os valores unitários. Somente em quatro casos (copo, feijão, marca texto e pilha) a modalidade de compra apresentou coeficiente estatisticamente significativo. Em um deles, inclusive, a dispensa de licitação resultou em preços menores quando se leva em consideração o volume de compras. Esses resultados, embora aparentemente contraintuitivos - porque se esperaria que os menores níveis de competição na dispensa de licitação levassem a preços maiores -, são consistentes com a percepção de que, no pregão eletrônico, os preços tendem a incorporar incertezas porque precisam vigorar, no caso do sistema de registro de preços, por dozes meses. 
Isso sugere que os limites de dispensa de licitação poderiam ser rediscutidos, embora seja preciso levar em consideração que o pregão eletrônico pode estar atuando como uma espécie de regulador de preços. É razoável supor, entretanto, que os limites de dispensa de licitação poderiam ser majorados de forma gradativa e com um monitoramento temporário a fim de que seja determinado um "ponto ótimo" para essa modalidade de aquisição.

\section{Referências}

AlbANO, G. L.; SPARRO, M. A simple model of frameworks agreements: competition and efficiency. Journal of Public Procurement, v. 8, n. 3, p. 356-378, 2008.

AlegriA, B. O. Dispensa de licitação: a necessária correção monetária da dispensa de licitação em razão do valor. 2016. 73 f. Monografia (Especialização MBA em Gestão Pública) - Instituto Ceub de Pesquisa e Desenvolvimento (ICPD). Centro Universitário de Brasília, Brasília, 2016.

ALEXANDRE, R. da S. Os fatores que influenciam na eficiência das licitações por meio do pregão eletrônico na UFPE. 2016. Dissertação (Mestrado em Administração) - Universidade Federal de Pernambuco, Recife, 2016.

Arantes, T.; Sforsin, A. C. P.; Pinto, V. B.; Martins M. C. Avaliação dos desfechos licitatórios na modalidade pregão eletrônico de um hospital universitário. Revista de Administração de Saúde, São Paulo, v. 19, n. 76, 2019.

BAILY, J. S. Ethnomusicology, intermusability, and performance practice. In: STOBART, Henry (ed.). The vew (ethno) musicology. Chicago: Scarecrow Press, 2008.

BANDIERA, O.; Prat, A.; VAlletTI, T. Active and passive waste in government spending: evidence from a policy experiment. American Economic Review, v. 99, n. 4, p. 1278-1308, 2009.

BARBOSA, E. G. Externalidades da pesquisa de preços nas licitações sob a modalidade pregão eletrônico: um estudo de caso no DNIT. João Pessoa: Instituto Federal de Educação, Ciência e Tecnologia da Paraíba, 2016.

BRASIL. Ministério do Planejamento. Catálogo de Materiais - CATMAT. 2012. Disponível em: https://cutt.ly/buvfUlv. Acesso em: 30 mar. 2020.

Carvalho Filho, J. dos S. Manual de Direito Administrativo. 28. ed. São Paulo: Atlas, 2015.

CHARNET, R. et al. Análise de modelos de regressão linear com aplicações. Campinas: Unicamp, 1999. 
CIBILS, F. G. Pregão eletrônico: uma análise de sua utilização em um órgão público federal sob o aspecto da economicidade. Porto Alegre: Repositório Digital, UFRGS, 2019.

CONTROLAdORIA-Geral DA UnIÃo (CGU). Nota Técnica no 1.081 2017a CGPLAG DG SFC.PDF. 2017. Disponível em: https://cutt.ly/tuvfHZC. Acesso em: 30 nov. 2019.

Cordeiro, G. M.; DemÉtrio, C. G. B. Modelos lineares generalizados e extensões. Piracicaba: USP, 2008.

FARIA, E. R.; FerReIRA, M. A. M.; SAntos, L. M.; SilveirA, S F. R. Fatores determinantes na variação dos preços dos produtos contratados por pregão eletrônico. Revista de Administração Pública (RJ), v. 44, n. 6, p. 1405-1428, nov./dez. 2010.

FIUZA, E. P. S. A agenda perdida das compras públicas brasileiras: rumo a uma reforma abrangente da lei de licitações e do arcabouço institucional. Rio de Janeiro: Ipea, 2014. Disponível em: https://cutt.ly/ouvf9ay. Acesso em: 11 dez. 2019.

hair, J. F.; BlACK, W. C.; BABIn, B. J.; Anderson, R. E.; TAtham, R. L. Análise Multivariada de Dados. Porto Alegre: Bookman, 2009.

KUHN, R. O. O princípio constitucional da economicidade aplicado às fiscalizações de obras públicas rodoviárias. 2018. Monografia (Especialização em Auditoria de Obras Públicas Rodoviárias) - Universidade de Brasília, Brasília, 2018.

MooRE, D. F. Applied survival analysis using R. [S.I.]: Springer, 2016.

PAZ, S. J. F. A experiência com a utilização do pregão eletrônico nas aquisições de bens: o caso de unidades gestoras do Exército Brasileiro sediadas no Estado do Rio de Janeiro. Dissertação (Mestrado em Administração) - Fundação Getulio Vargas / Escola Brasileira de Administração Pública e de Empresas, Rio de Janeiro, 2016.

\section{Ernane Ferreira Bastos}

(D) https://orcid.org/0000-0002-5245-0287

Tenente-Coronel do Comando do Exército Brasileiro. Mestre em Administração Pública (IDP, 2020). Pósgraduado em Logística e Transporte pela Universidade de Miami - EUA (2010). Pós-graduado em Operações Militares pela Escola de Aperfeiçoamento de Oficiais (2008).

E-mail: ernanefirma@gmail.com

\section{Luiz Ricardo Cavalcante}

(iD) https://orcid.org/0000-0003-1894-7238

Consultor Legislativo do Senado Federal. Professor do Mestrado em Administração Pública do Instituto Brasileiro de Ensino, Desenvolvimento e Pesquisa (IDP). Mestre e doutor em Administração.

E-mail: luiz.ricardo.teixeira.cavalcante@gmail.com 